\title{
Service Oriented Architecture based SDI Model for Geographical Indication Web Services
}

\author{
Rabindra K. Barik \\ Research Scholar \\ GIS Cell, MNNIT \\ Allahabad, India
}

\author{
Arun B. Samaddar \\ Chief Academic Adviser \\ United Group of Institutions \\ Allahabad, India
}

\author{
Shefalika G. Samaddar \\ Asst. Professor \\ CSED, MNNIT \\ Allahabad, India
}

\begin{abstract}
The accelerated growth rate of the human intellectuality of any country warrants a rapid development of information infrastructural facility protecting their intellectual property. Basically determination of potential Geographical Indication (GI) is a necessity for timely protection of intellectual property of geographical characteristics. The process of determination and its subsequent filing for registration of GI remains manual in most of the developing and least developed nations. Apart from determination of potential candidature of GI and registration of GI, various types of analysis of existing GIs is one of the key issues to be tackled also for timely protection of GI.
\end{abstract}

The present work reports the development of an efficient interoperable Service Oriented Architecture (SOA) based GI SDI Model (Acronym: $\mathrm{GI}^{3}$ (Geographical Indication Information Infrastructure)) to provide better geospatial web services for different applications in terms of their functionality, ease of operation and performance as applied in various GI operation. The $\mathrm{GI}^{3}$ is modular and allows the publishing of web service descriptions as well as to submit requests to discover the web services of user's interests. The model supports integration of applications and uses thin-client architecture. Web Map Service (WMS), Web Features Service (WFS) and Web Catalogue Service (CS-W) of Open Geospatial Consortium (OGC) standards have been used for sharing and exchange of geospatial data pertaining to $\mathrm{GI}^{3}$. The open source GIS software, used for development of $\mathrm{GI}^{3}$, include Quantum GIS for creation of GI geospatial database, PostGIS for storing of spatial database, MYSQL for storing of security aspects of spatial and non-spatial data; ALOV, GeoServer, GeoNetwork, GeoWebCache and Apache Tomcat for imparting geospatial web capabilities and PHP (Hypertext Preprocessor), JSP (Java Server Pages) and GeoExt (Geo Extension) for dy namic server side scripting. The developed $\mathrm{GI}^{3}$ presently provides detailed information about all the existing GIs and proposed GIs of India as a test case and aims to deliver spatial information related to GI at affordable cost and is expected to be beneficial to the general and power users. The same may be used in future for other countries on expanding the volume of spatial data to include the Globe.

\section{Keywords}

Geographical Indication, Intellectual Property Rights, SDI, Open Source GIS, SOA, GI ${ }^{3}$

\section{INTRODUCTION}

Intellectual Property Rights (IPR) refers to a number of distinct types of creations of the mind for which property rights are recognized having legal validity. There are seven types of IPR like Patents (Act passed in the Indian Parliament $10^{\text {th }} \mathrm{March}$, 1999), Copyright (Act passed in the Indian Parliament 30th December, 1999), Trade Marks (Act passed in the Indian Parliament on $23^{\text {rd }}$ December, 1999), Geographical Indications (Act passed in the Indian Parliament on $23^{\text {rd }}$ December, 1999), Industrial Design (Act passed in the Indian Parliament on the year 1999), Plant Variety Protection and Farmer's Right (Act passed in the Indian Parliament on August, 2001) Lay out of Integrated Circuit Design (Act passed in the Indian Parliament, 2000).

The accelerated growth rate of the human intellectuality of any country warrants a rapid development of information infrastructural facility protecting their intellectual property. Basically determination of potential Geographical Indication (GI) is a necessity for timely protection of intellectual property of geo graphical characteristics. Geographical Indication is a type of Intellectual Property Rights (IPR) as recognized in TRIPS Agreement [1][2].

There is a need to make coordinated efforts for availing information details in an integrated manner by integrating GIS, remote sensing and GPS technology [3]. For well organised information infrastructure of GI, Spatial Data Infrastructure (SDI) needs to be used and is increasingly being acknowledged as a national resource [4]. SDI is a portal where each stakeholder can access, use and exchange spatial and non spatial data for social, economic and environmental activities. Such a system at national level may have its nodes at State level and local level on Intranet and/or Internet on Global level.

Integration of GIS, remote sensing and GPS technology will provide an ideal infrastructure for GI. GI data contains both spatial and non-spatial data. The spatial data gets manipulated by GIS technology where as non-spatial data gets its treatment through a database server. There may be need to map spatial data to non-spatial data depending upon the functionality which can be achieved with ease in the proposed infrastructure.

GIS is a system of computer hardware and software that is designed to allow users to collect, manage, analyse and retrieve large volumes of spatially referenced data and associated attributes collected from a variety of sources [5]. The GIS has wider applications in decision making, storage of various kinds of data, bringing data and maps to a common scale for user need, superimposing, querying and analysing the large amount of data and designing and presenting final maps and reports to administrator and planner [6]. GIS can deal with large amount of spatial data at different scales as well as non-spatial data for 
deriving useful information in tabular/maps form for better understanding of organised development of infrastructure required for offering web services in GI [7].

\section{GEOGRAPHICAL INDICATIONS MANAGEMENT: INDIAN SCENARIO}

Geographical indications, in relation to goods, means an indication which identifies such goods as agricultural goods, natural goods or manufactured goods as originating, or manufactured in the territory, where a given quality, reputation or other characteristics of such goods is essentially attributable to its geographical origin and in case where such goods are manufactured goods, one of the activities of either the production or of processing or preparation of the goods concerned takes place in such territory, region or locality, as the case may be [8][9]. More than 5000 geographical objects are considered having potential for acquiring GI, other than 223 (till $23^{\text {rd }}$ September 2010) already registered ones [10] in India [11][12].

However, the information so far are available only in the form of published bulletins from different agencies, or at some specific websites in the form of reports. The database for such purpose is updated periodically from the application database of GI either from IPAB or from IPINDIA, Chennai [13]. None of them is comprehensive enough for ready application or easily available for analysis of GI related information.

Thus, the role of a GIS based information system in GI from the perspective of the user is an urgent need. In the present era of information age, new tools and technologies are required to collect, store, retrieve and analyze various types of information related to GI [14]. In fact, most of the bio-pirated resources would get required timely protection using the SDI model for GI. This paper provides a viable solution towards successful tackling of bio-piracy. These challenges cause barriers in extensively sharing GI data and restrain the effectiveness in understanding and responding to proper management. To overcome these challenges, Service Oriented Architecture based Spatial Data Infrastructure (SDI) needs to be used and the need is increasingly being acknowledged [15][16].

\section{SOA BASED SDI}

Spatial Data Infrastructure (SDI) provides an environment within which organisations interact with technologies to foster activities for using, managing and producing geographic data. It is the technology, policies, standards, human resources, and related activities necessary to acquire, process, distribute, use, maintain and preserve spatial data [17][18]. The core components of SDI can be viewed as policy, networking, standards, people and data [19][20].

An integrated SDI model only provides spatial data, value-added services for end-users, but also involves other important issues regarding interoperability, pluggability, security, policies and networks also. The SDI is a web based system developed under GIS environment. Thus, geospatial web service is an integral and important part of any SDI [21]. Geospatial web capabilities indicate to a web based GIS which can be modelled using the client-server architecture. A thin client model is desirable where most of the processing takes place on demand in the server and the client does not perform any heavy task other than displaying the data on screen [22]. The thin client system comprises of the two parts, the client and the server. This model is shown in Figure 1.

Client Side Server Side

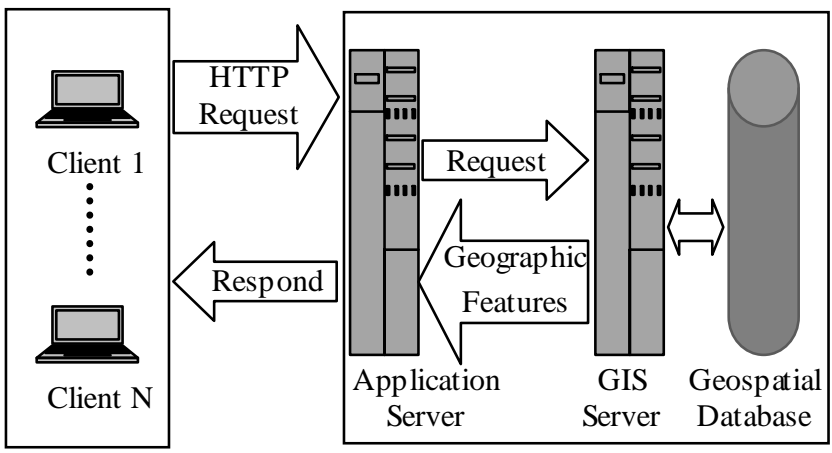

Figure 1: Thin dient GS Architecture [23]

The advantage of this model is that users will not be required to install any additional software apart from a standard web browser. Since processing will be done on the server side, clients will not need a powerful machine to access the services offered, though this would also mean that the server would be subjected to additional and often heavy loads due to processing.

The service oriented architecture recognizes such processing load and tries to construct a distributed, dynamic, flexible, and re-configurable service system over Internet that can meet information and service requirements for development of SDI. The key component in the SOA is service and a chaining system of services through composition of services i.e. a well defined set of ordered actions. It is self contained, stateless, and does not depend on the state of other services [24]. Figure 2 shows three major functionalities in SOA based SDI.

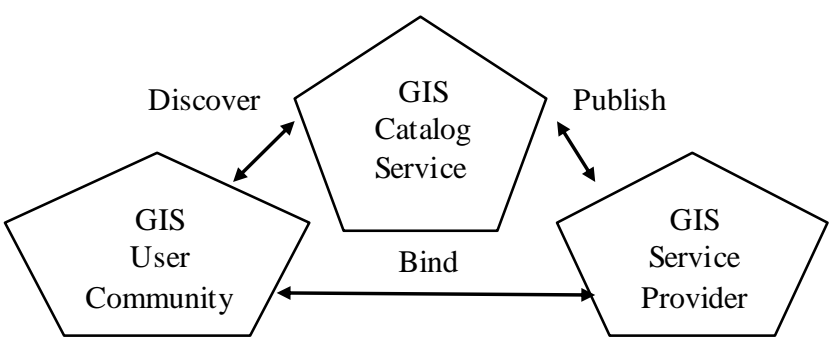

Figure 2: Three major functionalities in SOA [25]

In development of SDI, the major focus has been on SOA based geospatial web service by using spatial data. The services can be grouped into data service, processing service and catalog service. Data service is tightly coupled with specific data sets on which it operates and offers Web Feature Service (WFS), Web Mapping Service (WMS) and Web Coverage Service (WCS) [26]. The basic operations in SOA include publish, find and bind. To be able to be integrated into any service into SOA based architecture, it should make use of at least one of the SOA's defined operations. 
In SOA based SDI, there are three types of key actors i.e. service requester or GIS user community, GIS service provider and GIS catalog service. Catalog service can also be called registry service or broker service. However, the functionality remains same in most of the applications. Catalog service helps the requestors to discover or find the appropriate services. When a service provider sets up a service over the Internet and wants the users to use their service, it needs to publish their services using 'publish' operation.

\section{OBJECTIVE OF THE PRESENT WORK}

The main aim of the present work is development and implementation of SOA based GI SDI model (Acronym: $\mathrm{GI}^{3}$ (Geographical Indication Information Infrastructure)). It is proposed to use Quantum GIS for creation of geospatial database, PostGIS and MYSQL for storing of spatial and nonspatial data, ALOV, GeoServer, GeoNetwork, GeoWebCache, WAMP and Apache Tomcat for imparting geospatial web capabilities in terms of Web Map Service (WMS), Web Feature Service (WFS), Web Catalogue Service (CS-W) and PHP: Hypertext Preprocessor, JSP: Java Server pages and GeoExt: Geo Extension for dynamic server side scripting for development of $\mathrm{GI}^{3}$.

\section{METHODOLOGY ADOPTED}

For development of $\mathrm{GI}^{3}$, the main focus has been on the use of a practical approach to explore and extend the concept of SDI in Intellectual Property management sector. The developed $\mathrm{GI}^{3}$ should provide an effective and efficient means of sharing geospatial data and non-spatial data on the web using GIS in a secure way. Figure 3 shows the proposed SOA based SDI architecture of GI in which the basic over view of service provider, service consumer and catalog service are being shown.

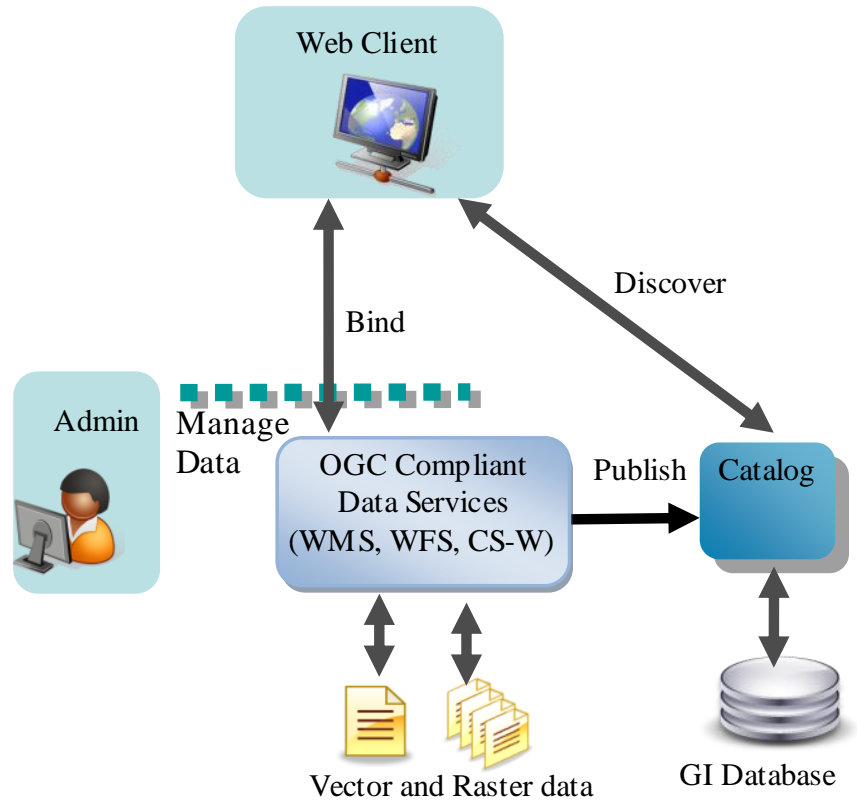

Figure 3: SOA based SDI workflow for GI

In $\mathrm{GI}^{3}$, it focuses on Open Geospatial Consortium (OGC) compliant web services using vector and raster data. Admin is the system administrator. Admin is managing the data and gives authority to the different user. There are various categories of administrative services. For example, Catalog is updated by catalog admin. This architecture fulfils the most sophisticated workflow for development of $\mathrm{GI}^{3}$. Figure 4 shows the flow of information for the development of $\mathrm{GI}^{3}$ in the present work.

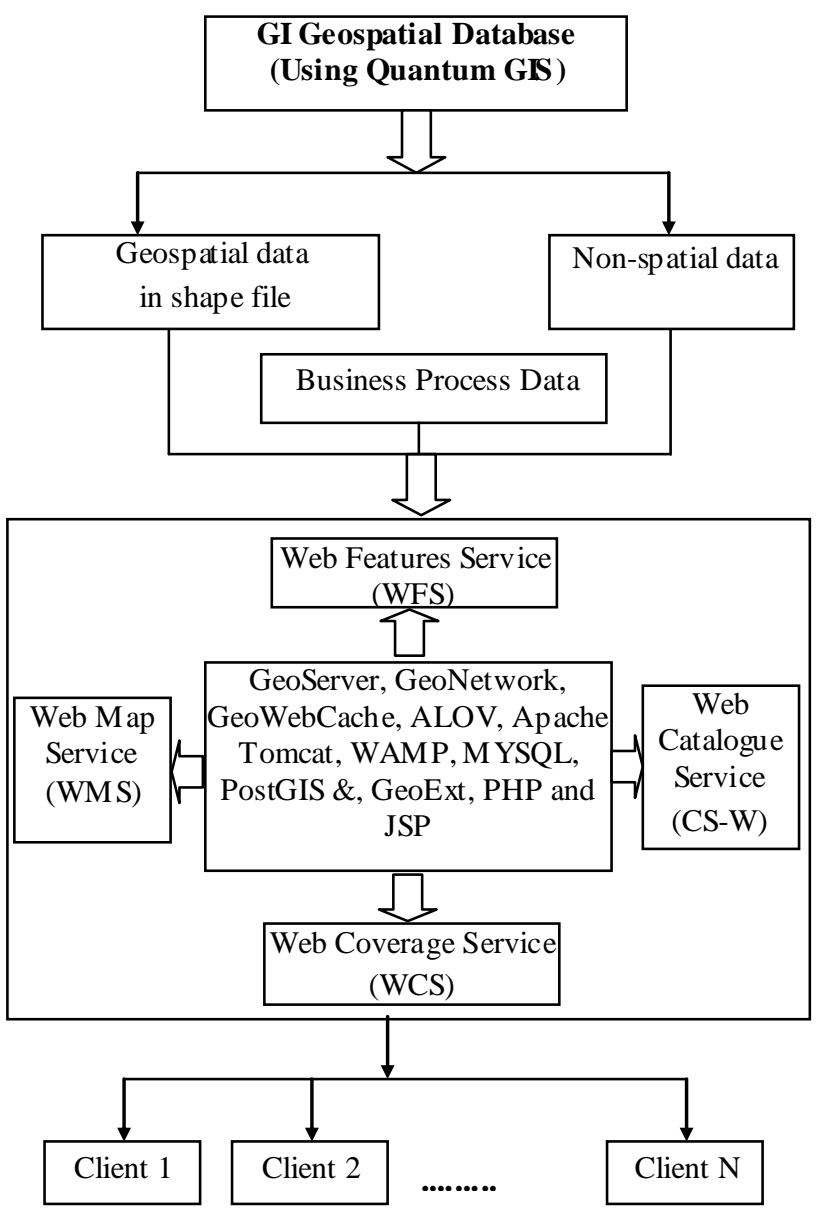

Figure 4: Flow Chart of the proposed methodology

Figure 5 shows the layered architectural view that comprises of open source resources. 


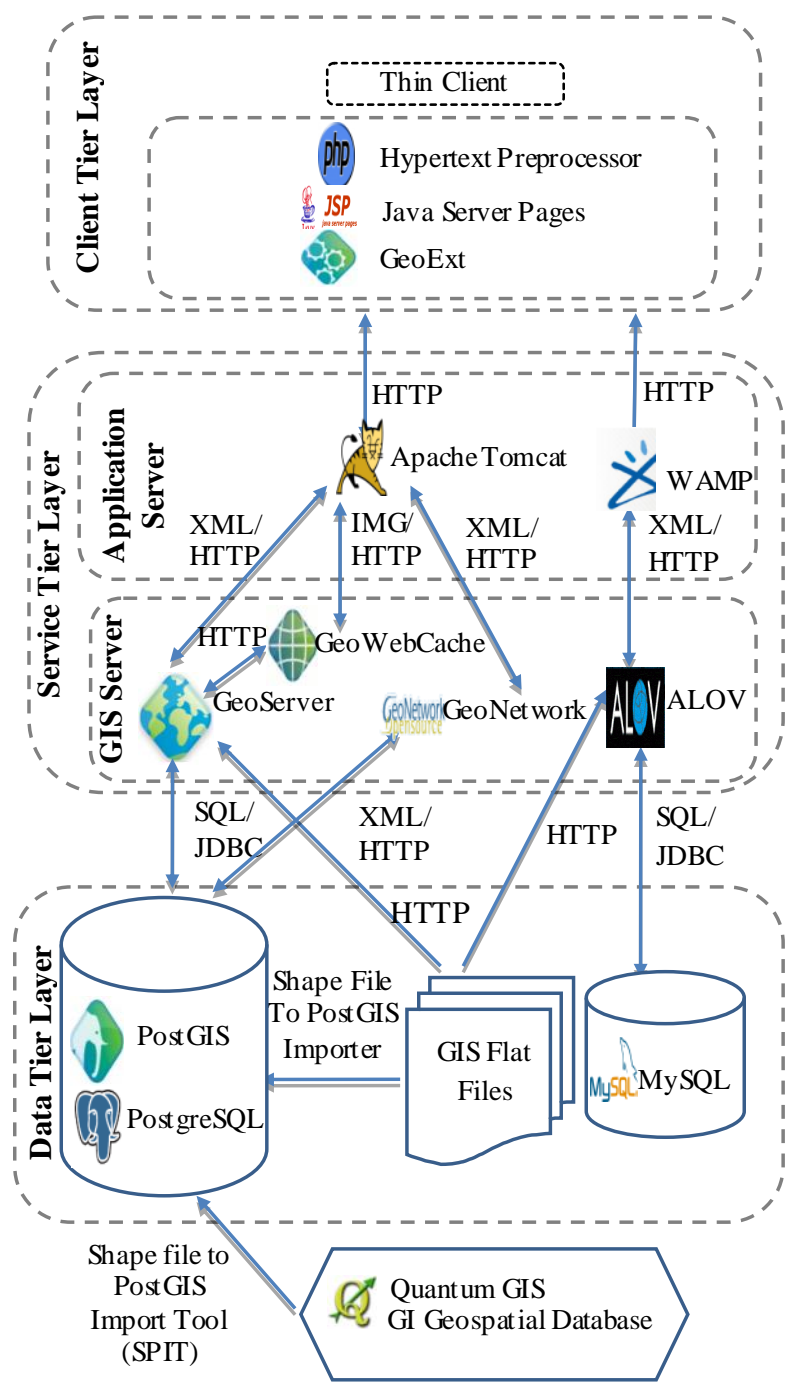

Figure 5: Layered Architectural view of open source resources

For the creation of integrated GI Geospatial Database, the present framework uses Quantum GIS open source GIS software. ALOV, GeoServer, GeoNetwork, GeoWebCache, WAMP. Apache Tomcat have been integrated for imparting the geospatial web capabilities with respect to WMS, WFS and CSW services [27]. PostGIS and MYSQL are used for storing of spatial and non-spatial data for decision making. PHP: Hypertext Pre-processor, JSP: Java Server Pages and GeoExt: GeoExtension lan guages have been used for dy namic server side scripting in the framework. In the present work, WAMP and Apache tomcat servers have been configured as per requirement of $\mathrm{GI}^{3}$ and then PHP, JSP and GeoExt scripting lan guages are used for sharing of the geospatial data and non-spatial data and for publication of maps related to GI on the web.

\section{PROTOTYPE DEVELOPMENT}

The prototype development of $\mathrm{GI}^{3}$ is based on Jacobson's method of Object Oriented Software Engineering (OOSE) method which involves the formation of models that capture the actors of the system and their behaviour for each of the design stages [28][29]. The models are made up of objects representing real world entities. This is a natural way to describe the environment in which the sy stem and its actors would be groomed in a evolving manner. This helps in reducing the semantic gap between the developed model and the real world application. Figure 6 shows the complete process model for development of $\mathrm{GI}^{3}$.

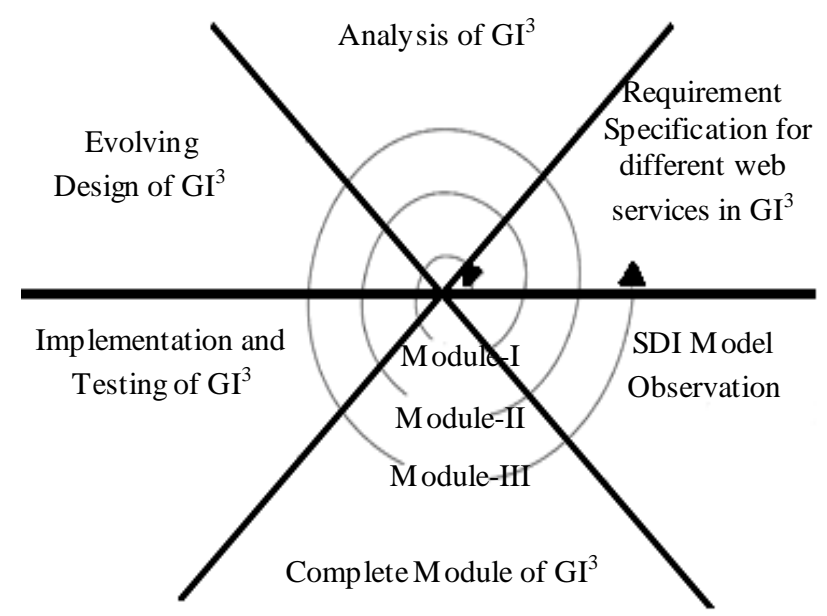
Figure 6: Process Model for $\mathbf{G I}^{3}$ - Customization of Win-
Win Spiral model

In OOSE approach, the software development process adopts a sequence of steps including requirements specification, analysis and design, implementation and testing, complete module and model observation. The process is usually cyclic or incremental in nature and each implementation refines the analysis and design stages through evaluation and testing of a completed module. Further, the incremental development strategy allowed the problem of constructing this framework to be tackled in smaller, more manageable portions of increasing complexity, called modules. In addition, it is expected that each module would reveal unique features related to the requirements of the underlying infrastructure based web services and enable exploration of the interfaces between SDI components.

\subsection{Requirement Specifications}

The requirements stage of application design aims to specify the behaviour of the framework from the perspective of a user. A use case specifies a sequence of actions, including variants that the system can perform and yield an observable result of value to a particular actor [29].

Figure 7 shows the Use Case Model which specifies how a user would interact with the system to identify the various system objects and highlights the need for careful consideration to be given to these issues of human computer interaction with in the network environment. 


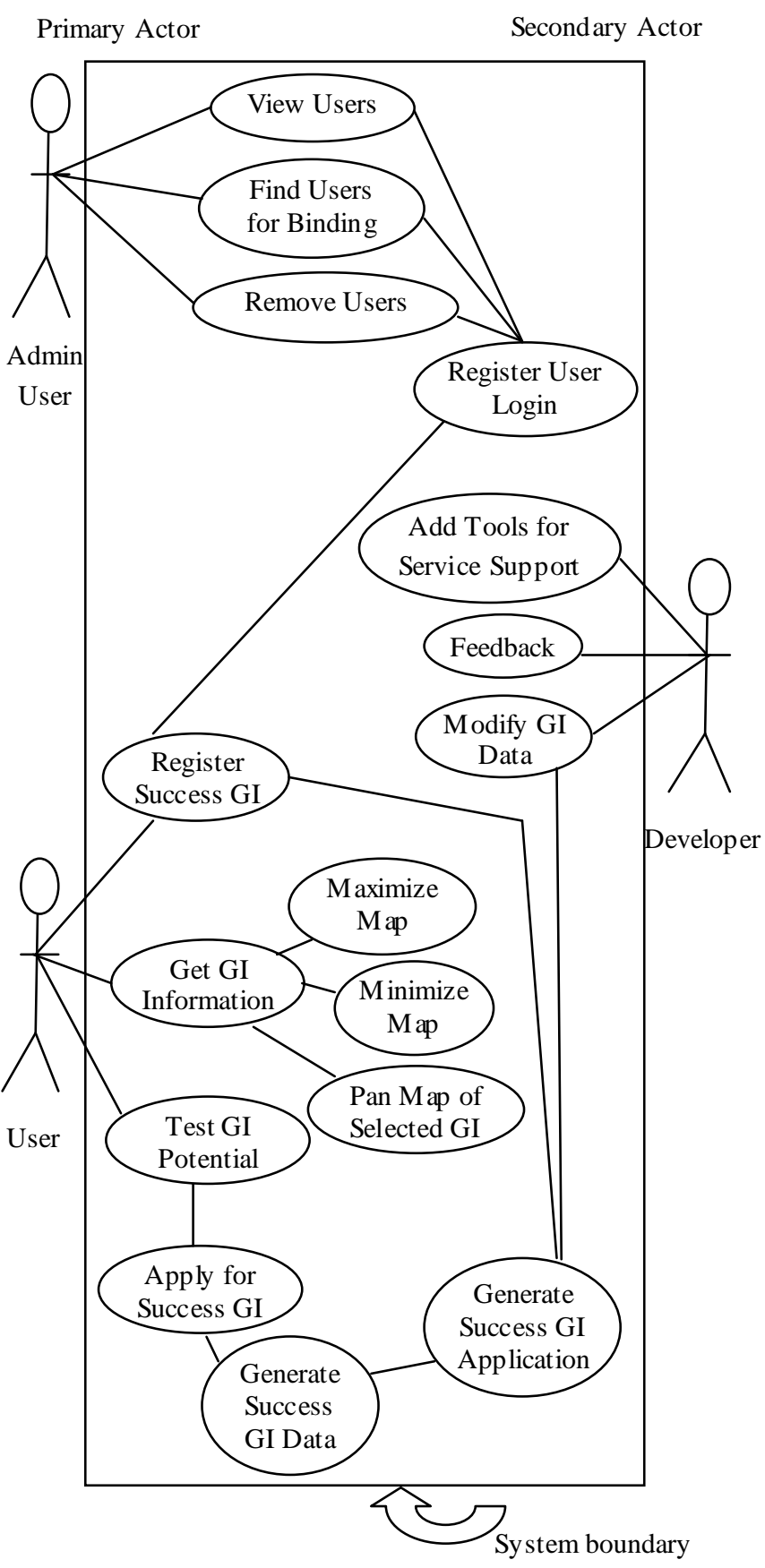

Figure 7: Prototype of Use Case Model

In the present work, the use case model has been associated with three types of users, i.e., administrative user, general user and developer. The administrative user will have the authority to view, delete and find existing users which are associated with this system. The general user has the variety of option like login, logout, register, get-information, maximize map, minimize map, pan feature, get-coordinate, upload files and download files. The developer is associated with the system in terms of user tools, modifying the existing system and collecting the feedback on the system. Other GI specific operations are being used by the actors depending upon a guard condition. These conditions are not presently associated in the Use case model in order to simplify the use case model. Such annotations are characteristic of domain model or class diagram.

Even an object diagram can have different annotations depending on guard conditions. System sequence diagrams depict the flow of actions in a sequence considering one action at a time. The domain model (complete or partial) is obtained on the basis of all the above models and that completes the modelling the static nature of the application. The dynamic nature of the application is captured through a number of modelling schemes like action diagram, collaboration diagram, state chart diagram etc.. The complete modelling of $\mathrm{GI}^{3}$ is out of scope of this paper. Interested readers may contact the corresponding author for such investigation, that has been successfully implemented in http://ipsrd.mnnit.ac.in/localsdi. A number of modelling schemes are used for analysis, further refinement and subsequent design.

\subsection{Analysis and Design}

Translating the user requirements into an interface and the underlying algorithms for formulation of prototype falls within the analy sis portion of the OOSE life cycle. The thematic layers created include maps of India with state boundaries and different GI location detailing information with distinguished name of concerned GI. Presently 223 GI has been registered (till $23^{\text {rd }}$ September 2010) [30]. In GI registered data most of the GIs have been registered in India and are stored to be updated periodically. The flow of processes in the system is captured in the form of state chart diagram that need to be translated into design element of the software. In present work, class diagram, sequence diagram, collaborative diagram and activity diagram describe the workflow behaviour of $\mathrm{GI}^{3}$ and are shown in Figure 8, Figure 9, Figure 10 and Figure 11 respectively.

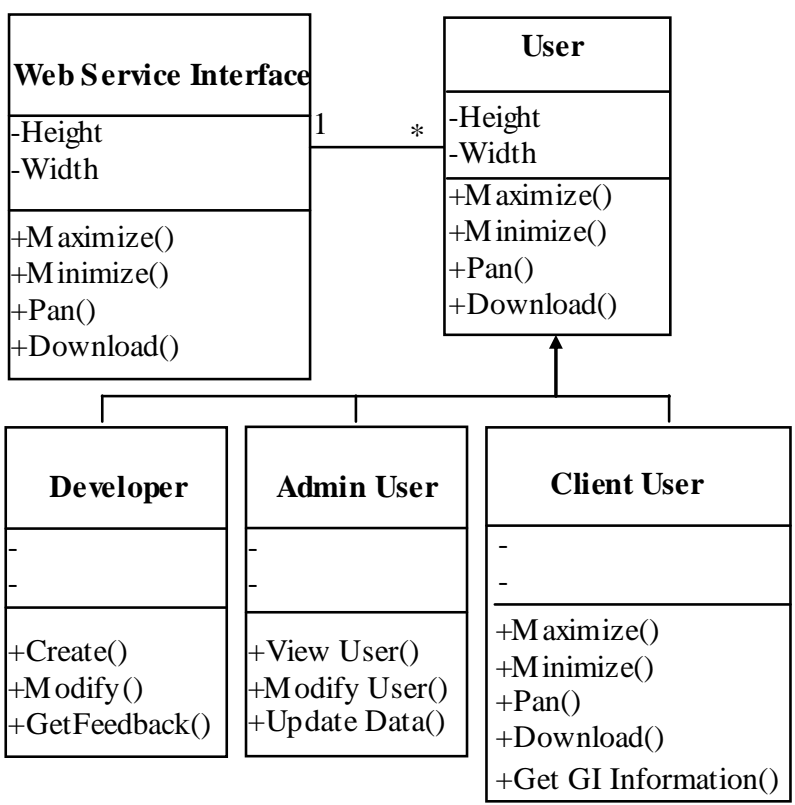

Figure 8: Class Diagram for $\mathrm{GI}^{3}$ (Partial domain model) 
The partial domain model presented in Figure 8 evolves over an iterative cy cle of preparation of UML design elements.

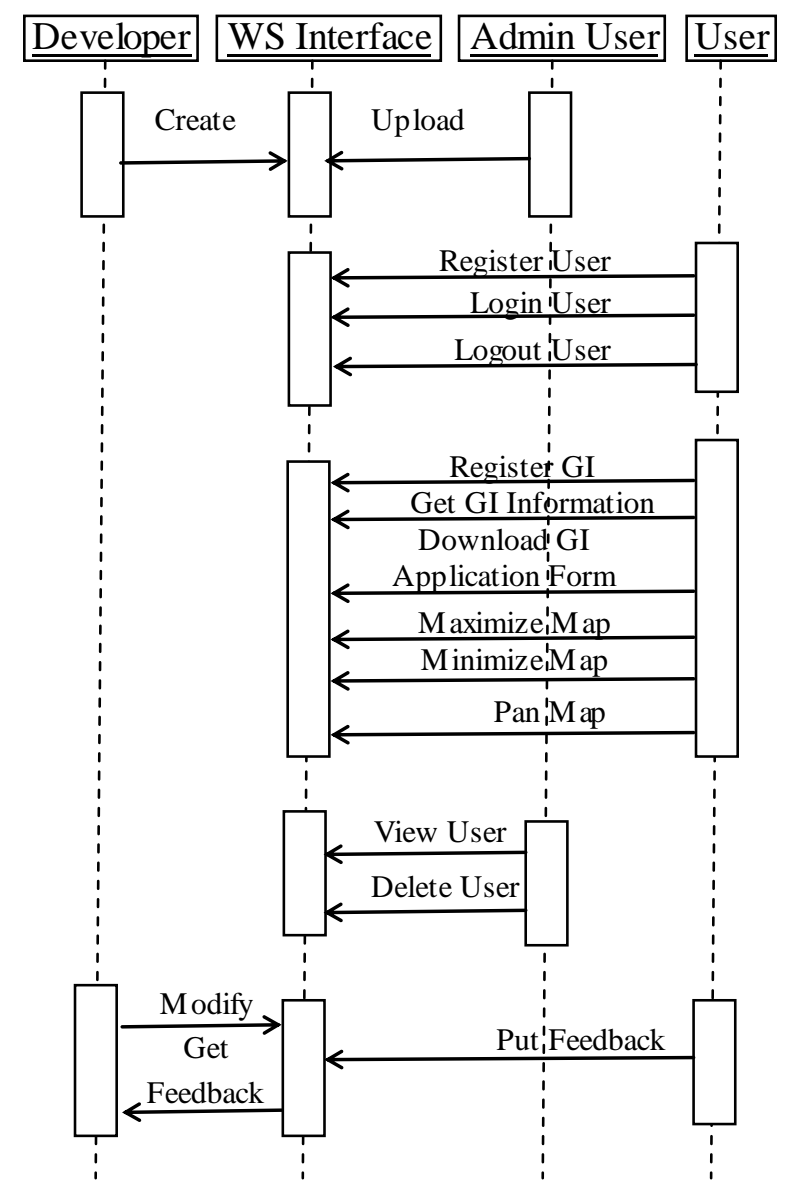

Figure 9: Sequence Diagram for $\mathrm{GI}^{3}$ (Best case scenario)

The sequence diagram in Figure 9 presents a best case scenario. This success story should be duly associated with a number of alternative scenarios to be invoked at each step. The alternative scenarios are not presented and require the involvement of real life environment.

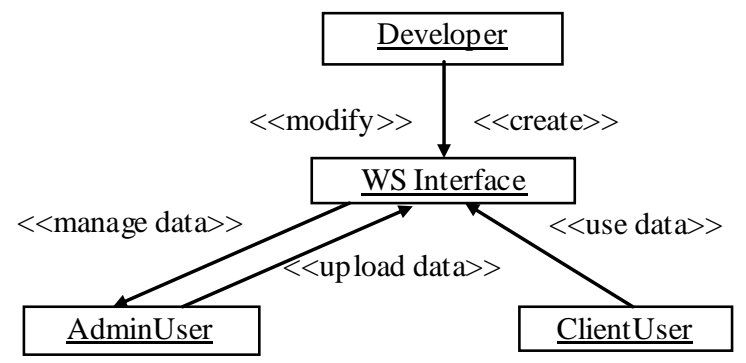

Figure 10: Collaborative Diagram for $\mathrm{GI}^{3}$ (Rough cut)

Similarly, Figure 10 presents only a rough cut of the first iteration of collaborative diagram.

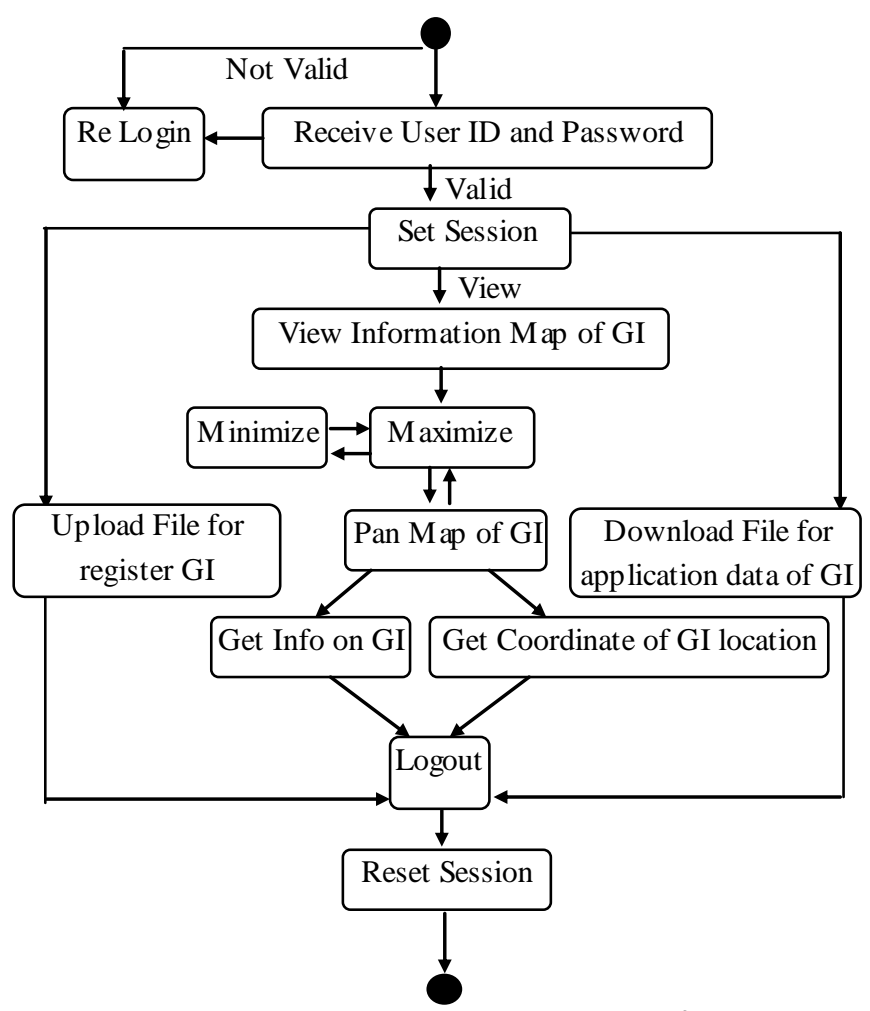

Figure 11: Activity Diagram for $\mathbf{G I}^{3}$

A preliminary activity diagram, as a result, is obtained in Figure 11.

\subsection{Implementation and Testing}

The overall requirements of the framework that are defined in the design phase are implemented and used for testing the appropriate parameters. The implementation is done by keeping the planning and design concepts in mind. In the prototype development, interface design is one of the challenging tasks for achieving the real success. The implementation is performed in the PHP environment and follows the incremental option. The testing phase is essential for increasing the QOS (Quality of Service) and reliability of the software. $\mathrm{In} \mathrm{GI}^{3}$, the testing is done in accordance to the iterative model after the prototype is developed for the whole process.

\subsection{Complete Module}

The framework consists of three main modules, e.g., module I for registration, module II for GI Information Mapping, and module III for Utility Services. Module I describes the detailed process to register the user for authentication. After registration process, user can use the framework with various operations like registering a GI with a resumed or new application, testing a potential GI, generating potential GI data for application, generating application of registration checking for bio-piracy region wise, application linking for global GI, various GI associations, licensing of GI etc. Module II gives detailed viewing GI information mapping in terms of various factors associated with availability in India. Module III describes utility services, i.e., management of user level security aspects, and uploading/ downloading features for all operations mentioned 
above in the activity diagram.

\subsection{GI $^{3}$ Model Observation}

The $\mathrm{GI}^{3}$ framework developed has been shown using three illustrations. Figure 12 shows the GI database creation in Quantum GIS.

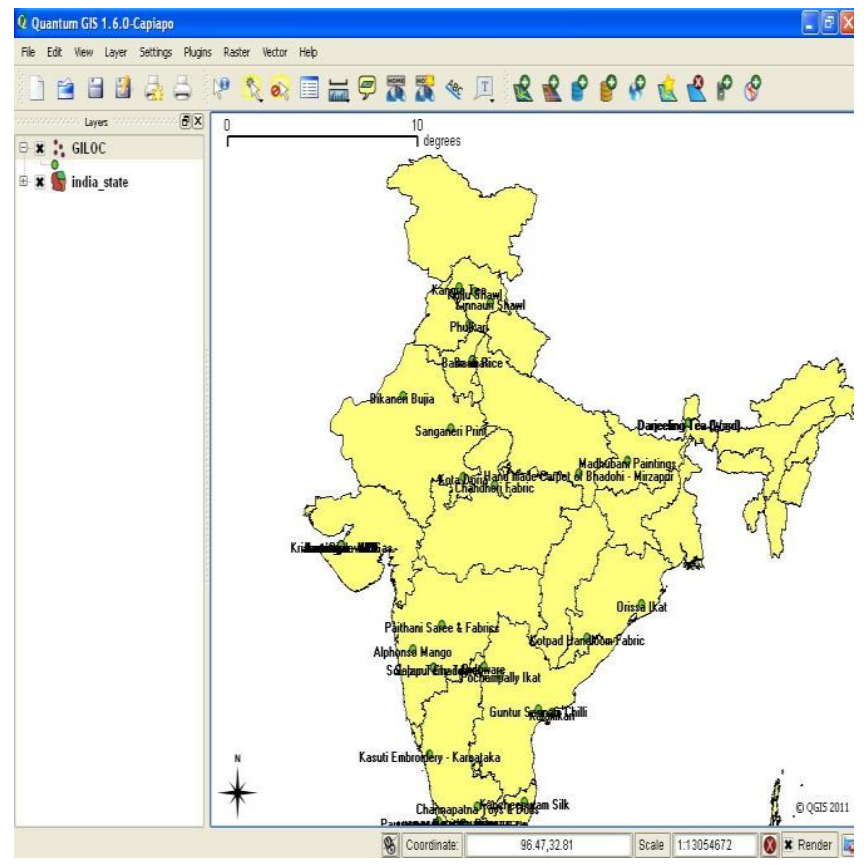

Figure 12: GI Database Creation in Quantum GIS

Figure 13 shows all the registered GI locations in India with detail information.

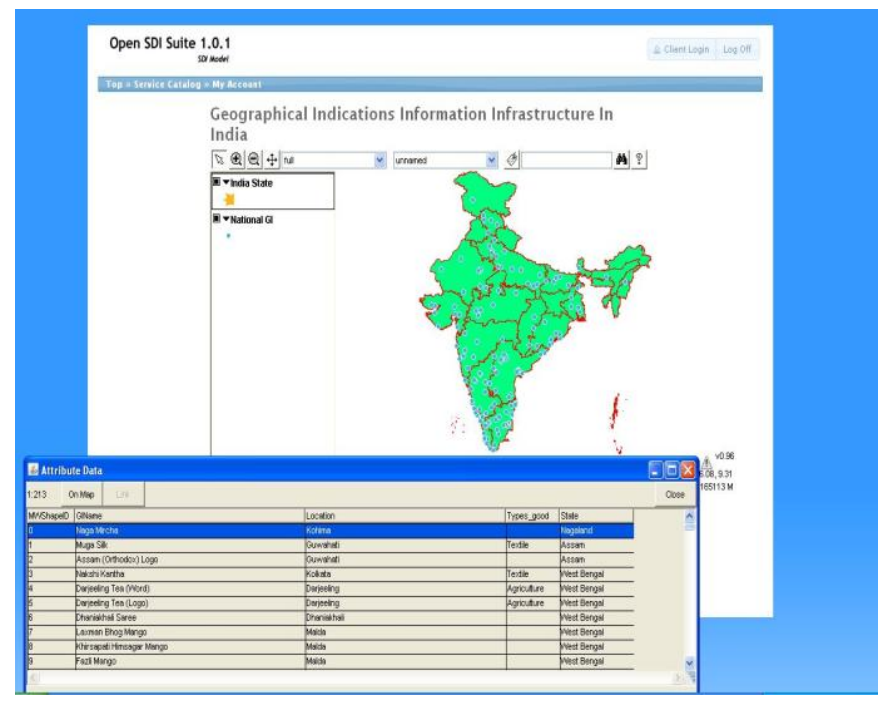

Figure 13: Map showing GI locations in $\mathbf{G I}^{3}$

\section{CONCLUDING REMARKS}

A prototype SOA based SDI Model Geographical Indication Information Infrastructure $\left(\mathrm{GI}^{3}\right)$ has been developed using open source GIS. The present research work is focused at adopting OGC standards for registering, creating, accessing, integrating, sharing and testing the GI information on the web. The developed framework adopts a modular and flexible structure, and provides an efficient mechanism for the generation and delivery of value-added spatial information to extend the concept of SOA based SDI Model in the field of Intellectual Property particularly in Geographical Indication at national level. The experience in using open source GIS software suggests that various tools and software like Quantum GIS, ALOV, Geoserver, GeoNetwork, GeoWebCache, Apache Tomcat, MySQL, PostGIS, PHP, JSP and GeoExt are available for creation of spatial datasets and implementation of geospatial web services in comparison to costly proprietary solutions.

The developed SOA based SDI model for management of GI will also provide the basic components for delivery of information efficiently at affordable costs and is expected to be beneficial to different user community on global platform. These model can be well suitable to expand GI information for other countries as well with suitable adaptation in data tier of the model.

\section{REFERENCES}

[1] Internet-1: http://www.ipindia.nic.in/girindia/, Geographical Indication registry (Accessed on $21^{\text {st }}$ October 2010).

[2] Notification of the Geographical Indications of Goods (Registration and protection) Rules, 2002, Gazette_of_India_Extraordinary, Part II Section 3, Sub section (i) Extraordinary, 8th March, 2002, Ministry of Commerce \&Industry (Department of Industrial Policy and Promotion).

[3] Ramachandra, T.V. and Kumar, Uttam., 2004. Geographic Resources Decision Support System for Land Use, Land, Cover Dynamics Analysis, Proceedings of the FOSS/GRASS User Conference 12-14 September, 2004, Bangkok Thailand.

[4] Gupta, R.D., Samaddar, Arun B., Barik, R.K., Madden, Marguerite, 2009. Open Source GIS based Framework for Development of Health GIS, $3^{\text {rd }}$ International Conference on Health GIS 2009, July 24-26, 2009 at Hyderabad, India and organised by AIT, Bangkok.

[5] Morris Steven P., 2006. Geospatial Web Services and Geo archiving: New Opportunities and Challenges in Geographic Information Services. LIBRARY TRENDS, Vol. 55, No. 2, Fall 2006 ("Geographic Information Systems and Libraries," edited by Jaime Stoltenberg and Abraham Parrish), pp. 285-303.

[6] Broueckner, Michael and Tetiwat, Orasa, 2008. Use of Geographical Information Systems for Thailand. E-leader, Bangkok.

[7] Ray, Sujit, Samaddar, Shefalika Ghosh, and Keserwani, Pankaj, 2011. An Efficient Architecture of Decision Support System for testing Potential Geographical Indication in India, The IEEE International Conference on 
Control, Robotics and Cybernetics, March 2011, New Delhi, India.

[8] Internet-2: http://www.geographicindications/index.htm, Geographical indication (Accessed on $25^{\text {th }}$ October 2010).

[9] Internet-3: http://www.ipsrd.mnnit.ac.in (Accessed on 24th March 2011)

[10] Geographical Indications Journal No. 30 Government of India in IPIndia on September 16, 2010.

[11] Samaddar, Shefalika Ghosh \& Samaddar, Arun B., 2010. Komal Chaul: A Potential Candidate for Geographical Indication, Journal of Intellectual Property Rights, VOL 15, May 2010, NISCAIR CSIR, New Delhi, India, pp 214-219

[12] Ganguli, Prabuddha, Journal on Geographical Indications Its evolving contours, MVIRDC WORLD TRADE CENTRE MUMBAI, 2009, SVKM's NMIMS University's Institute of Intellectual Property studies at http://www.iips.ac.in (Accessed on $25^{\text {th }}$ October 2010).

[13] Internet-4: http://www.nipo.in (Accessed on $25^{\text {th }}$ October 2010).

[14] Haj Mar Hlaing, Thida Oo and Aung Kyaw Oo, 2005. Implementing a Decision Support System (DSS) for discriminating herbal and medicinal plants in Myanmar using Classification Technique, 3rd International Conference on Computer Application.

[15] Samaddar, Arun B., Barik, R.K. and Gupta, R.D., 2010. Web GIS for Mineral Resources Management in India, $3^{\text {rd }}$ Asian Mining Congress, Jan. 22-25, 2010, Hotel Taj Bengal, Kolkata, India. Vol. 2, ISBN: 978-81-8211069-4, PP 349-358.

[16] Becker, Christoph ., Kulovits, Hannes., Rauber, Andreas ., Hofman, Hans., Plato, 2008. A Service Oriented Decision Support System for Preservation Planning JCDL June 1520, 2008, Pitsburgh, Pennsylvania, USA.

[17] Rawat, Sujata, 2003. Interoperable Geo-Spatial Data Model in the Context of the Indian NSDI. Thesis (Master), ITC, The Netherlands.

[18] Puri, Satish K., Sahay, Sundeep and Georgiadou, Yola, 2007. A Metaphor-Based Sociotechnical Perspective on Spatial Data Infrastructure Implementations: Some Lessons from India. Research and Theory in Advancing Spatial Data Infrastructure Concepts, ESRI Press, pp.161-17.

[19] Mansourian, A., Rajabifard, A., Valadan Zoej, M.J. and Williamson, I., 2005. Using SDI and web-based system to facilitate disaster management. International Journal of Computers \& Geosciences, Vol. 32, pp. 303-315.

[20] Rajabifard, A., Feeney, M. E. F. and Williamson, I. P., 2002. Future Directions for SDI Development. International Journal of Applied Earth Observation and Geoinformation, ITC, The Netherlands, Vol. 4, No. 1, pp. 11-22.

[21] GSDI Cookbook, 2004. Developing spatial data infrastructure: The SDI Cookbook (online). Available from: http://www.gsdi.org/docs2004/Cookbook/ cookbookV2.0.pdf. (Accessed: 15 November, 2008).

[22] Harper, Eric, 2006. Open Source Technologies in Webbased GIS and Mapping, Master's Thesis, Northwest Missouri State University, Mary ville Missouri.

[23] Alesheikh , AA., Helali, H. and Behroz, HA. 2002. WebGIS Technologies and Application, Symposium on Geospatial Theory, Processing and Applications, Ottawa, ISPRS, Vol. XXXIV, Part 4.

[24] Xiaolin, Lu, 2005. An Investigation on Service Oriented Architecture for constructing Distributed WebGIS Application, IEEE International Conference on Services Computing (SCC'05), vol. 1, pp.191-197.

[25] Vaccari, Lorenzino, Shvaiko, Pavel and Marchese, Maurizio, 2009. A geo-service semantic integration in Spatial Data Infrastructure, International Journal of Spatial Data Infrastructures Research, 2009, Vol.4, pp. 24-51.

[26] OGC, 2004. Open GIS Web Map Server Cookbook (online). Available from: http://www.opengeospatial.org/standards/wms (Accessed: 12 September, 2008).

[27] Barik, R.K., Samaddar, Arun B. and Gupta, R.D., 2009. Investigations into the Efficacy of Open Source GIS Software, International conference, Map World Forum, on Geospatial Technology for Sustainable Planet Earth, Feb 10-13, 2009, Hyderabad, India.

[28] Mall, Rajiv, 2004. Fundamentals of Software Engineering, Rev. $2^{\text {nd }}$ Edition, Prentice-Hall of India Pvt.Ltd, India.

[29] Davieffp, Jessica, 2003. Expanding the spatial data infrastructure model to support spatial wireless applications. Thesis (PhD). Department of Geomatics, The University of Melbourne.

[30] Geographical Indications Journal No. 36 Government of India in IPIndia on September 23, 2010. 